\title{
Development of a quadruple qRT-PCR assay for simultaneous identification of highly and low pathogenic H7N9 avian influenza viruses and characterization against oseltamivir resistance
}

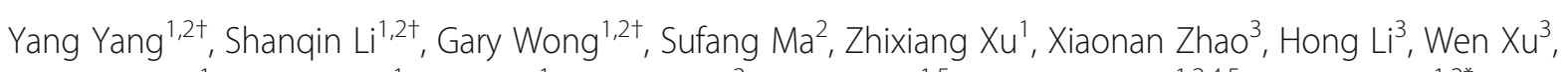

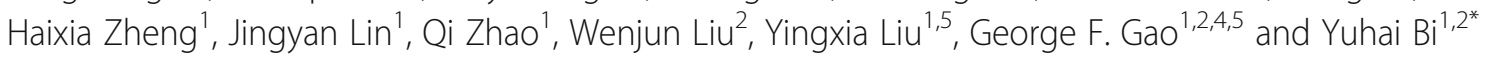

\begin{abstract}
Background: During the fifth wave of human H7N9 infections, a novel highly pathogenic (HP) H7N9 variant emerged with an insertion of multiple basic amino acids in the HA cleavage site. Moreover, a neuraminidase inhibitor (NAI) resistance (R292K in NA) mutation was found in H7N9 isolates from humans, poultry and the environment. In this study, we set out to develop and validate a multiplex quantitative reverse transcript polymerase chain reaction (qRT-PCR) to simultaneously detect the presence of H7N9 and further identify the HP and NAl-resistance mutations.

Methods: A quadruple qRT-PCR to simultaneously detect the presence of H7N9 and further identify the HP and NAl-resistance mutations was designed based on the analyses of the HA and NA genes of H7N9. This assay was further tested for specificity and sensitivity, and validated using clinical samples.

Results: The assay was highly specific and able to detect low pathogenic (LP)- or HP-H7N9 with/without the NAlresistance mutation. The detection limit of the assay was determined to be 50 genome-equivalent copies and $2.8 \times$ $10^{-3} 50 \%$ tissue culture infectious doses $\left(\mathrm{TCID}_{50}\right)$ of live H7N9 per reaction. Clinical validation was confirmed by commercial kits and Sanger sequencing with ten clinical samples.
\end{abstract}

Conclusions: We developed and validated a rapid, single-reaction, one-step, quadruple real-time qRT-PCR to simultaneously detect the presence of H7N9 and further identify the HP- and NAl-resistance strains with excellent performance in specificity and sensitivity. This assay could be used to monitor the evolution of H7N9 viruses in the laboratory, field and the clinic for early-warning and the prevention of H7N9 infections.

Keywords: Highly/low pathogenic avian influenza virus, H7N9, Quadruple qRT-PCR, Molecular diagnostics, NAIresistance, Oseltamivir

\footnotetext{
* Correspondence: beeyh@im.ac.cn

${ }^{+}$Yang Yang, Shanqin Li and Gary Wong contributed equally to this work.

'Shenzhen Key Laboratory of Pathogen and Immunity, State Key Discipline of Infectious Disease, Second Hospital Affiliated to Southern University of

Science and Technology, Shenzhen Third People's Hospital, Shenzhen

518112, China

${ }^{2}$ CAS Key Laboratory of Pathogenic Microbiology and Immunology,

Collaborative Innovation Center for Diagnosis and Treatment of Infectious

Disease, Institute of Microbiology, Center for Influenza Research and

Early-warning (CASCIRE), Chinese Academy of Sciences, Beijing 100101, China

Full list of author information is available at the end of the article
}

(c) The Author(s). 2018 Open Access This article is distributed under the terms of the Creative Commons Attribution 4.0 International License (http://creativecommons.org/licenses/by/4.0/), which permits unrestricted use, distribution, and reproduction in any medium, provided you give appropriate credit to the original author(s) and the source, provide a link to the Creative Commons license, and indicate if changes were made. The Creative Commons Public Domain Dedication waiver (http://creativecommons.org/publicdomain/zero/1.0/) applies to the data made available in this article, unless otherwise stated. 


\section{Background}

Since human H7N9 infection was first identified in 2013 [1], mainland China has experienced five waves of human infections [2, 3]. H7N9 virus infection caused acute respiratory distress syndrome and resulted in high morbidity and mortality [1, 4]. As of March 27, 2018, a total of 1567 cases of laboratory-confirmed H7N9 virus infections were identified with a case fatality rate of $\sim 39 \%$ (615 deaths) [5]. During the first four waves, the H7N9 viruses circulating in China were classified as low pathogenic (LP) avian influenza virus (AIV) carrying amino acid residues PKGR/G at the HA cleavage site, causing asymptomatic infection in poultry $[4,6]$. However, a highly pathogenic (HP) H7N9 AIV variant emerged during the fifth wave in 2017, and has since been identified in 28 human infections [7-10]. These HP-H7N9 isolates contained polybasic amino acids with a PKGKRTAR/G, PKGKRIAR/G, PKRKRAAR/G or PKRKRTAR/G in the cleavage site of HA proteins [2], which are associated with enhanced virulence in chickens $[2,11]$.

Antivirals play an important role in the management of influenza virus infections [12]. Neuraminidase inhibitors (NAIs) have been used as front-line therapeutic options since the novel H7N9 viruses contain the S31N mutation in the M2 protein, which confers resistance to the M2 ion channel blockers such as amantadine [1, 13]. However, studies have shown that the NA R292K (N2 numbering) mutation in H3N2 and H7N9 viruses [13-16], H274Y (N2 numbering) mutation in the seasonal H1N1, H1N1pdm09 and $\mathrm{H} 5 \mathrm{~N} 1$ viruses [17-21], emerged during the treatments or through spontaneous changes [14, 22, 23], resulted in a high level of resistance to oseltamivir and other NAIs. Furthermore, H7N9 viruses with the NA R292K mutation were frequently reported in the infected patients, and were usually accompanied by prolonged virus shedding and adverse clinical outcomes [7, 16, 24]. The continuous emergence of NAI-resistant viruses increases the potential threat of the H7N9 viruses to public [25].

Sensitive molecular techniques are needed for the rapid detection of HP-H7N9 variants and NAI-resistance to monitor its circulation, transmission and guide antiviral treatments in clinic. Currently, two qRT-PCR assays have been reported to identify HP-H7 or NAI-resistance mutation of H7N9 virus [26, 27]. However, the application may be restricted by the limit of detection and the circumscribed detection targets. To this end, we developed and validated a multiplex qRT-PCR to simultaneously detect H7N9 and further identify the HP and NAI-resistance strains, and the results are presented herein.

\section{Methods}

\section{Viruses and RNA extraction}

The strains of influenza A and B were previously isolated, and preserved by our group. Viral stocks were prepared in embryonated chicken eggs (Xinxing Dahuanong Biotechnology, Guangzhou, China) with the approval of Animal Ethics Committees from Shenzhen Third People's Hospital. Viral RNA was extracted from stocks using the QIAamp RNA Viral Kit (Qiagen, Heiden, Germany) according to the manufacturer's instruction. Viral RNA was eluted in $50 \mu \mathrm{L}$ of RNA-free buffer and stored at $-80{ }^{\circ} \mathrm{C}$ for subsequent use.

\section{Viral stock titration by $\mathrm{TCID}_{50}$}

MDCK cells (ATCC, Manassas, USA) in 96-well plates were grown to $90 \%$ confluence and infected with 10 -fold serial dilutions of the H7N9 chicken embryo allantoic fluid for $1 \mathrm{~h}$ at $37{ }^{\circ} \mathrm{C}$. Then the cells were overlaid with fresh DMEM plus TPCK-treated trypsin $(2 \mu \mathrm{g} / \mathrm{ml})$. At 3 days post infection (dpi), plates were assessed for the lowest dilution in which $50 \%$ of the wells exhibited cytopathology and HA titer. The 50\% tissue culture infectious dose $\left(\mathrm{TCID}_{50}\right)$ values were calculated according to the Reed-Muench method [28].

\section{Primer and probe design}

All the HA and NA sequences of H7N9 used in the present study were downloaded from the NCBI (National Center for Biotechnology Information) and GISAID (Global Initiative on Sharing All Influenza Data), and aligned using the MEGA 7.0 software. Regions covering the insertion mutation in HA cleavage site and the NAI-resistance mutation (R292K) in NA were chosen as the targets for the primer design. The primers and probes were designed using the Primer Premier 5 software. The probes were labeled with four different fluorescent reporter dyes including FAM, VIC, CY5, and ROX at the $5^{\prime}$-end. The FAM and VIC were labeled with the fluorescent quencher dye NFQ-MGB at the 3 '-end, while CY5 and ROX were labeled with BHQ. The sequences and genome positions of the primer and probe set are shown in Table 1.

\section{Generation of DNA standards}

A section of the HP-H7 and N9-K292 genes were amplified with the primers H7-F/H7-R and N9-F/N9-R, respectively. The PCR products were purified using the Gene JET PCR Purification Kit (Thermo, MA, USA) and ligated to the pGEM-T vector (Promega, Madison, USA). Plasmids were quantified using the Nanodrop 2000 Spectrophotometer (Thermo, MA, USA). The copy number (molecules $/ \mathrm{mL}$ ) was calculated using the following equation: $[\mathrm{C} \times \mathrm{A} / 660 \times \mathrm{L}]$, in which $\mathrm{C}$ represents the concentration of plasmid $(\mathrm{g} / \mathrm{mL})$ assessed by the optical density measurement; $\mathrm{A}$ is the Avogadro number $\left(6.023 \times 10^{23}\right) ; \mathrm{L}$ is the length of the plasmid (number of nucleotides); and 660 is an approximation of the molecular weight of a nucleotide $(\mathrm{g} / \mathrm{mol})$. 
Table 1 Primers and probes used in the multiplex qRT-PCR assay

\begin{tabular}{|c|c|c|c|}
\hline Primers/probes & Sequences $\left(5^{\prime}-3^{\prime}\right)^{a}$ & Genome positions $^{\mathrm{b}}$ & $\begin{array}{l}\text { Final } \\
\text { concentration (nM) }\end{array}$ \\
\hline $\mathrm{H} 7-\mathrm{F}$ & GGRAAATGYCCRAGATATGTTAA & 934-956 & 600 \\
\hline$H 7-\mathrm{R}$ & AATTAGKCCTTCCCATCCATTT & 1062-1083 & 600 \\
\hline H7-P-W & ROX-TTGGTGCYATAGCDGGTTTCATTGA-BHQ2 & 1037-1061 & 600 \\
\hline H7-P-M & FAM-AGRGAAAACGGRYTGCGA-MGB & 1010-1027 & 800 \\
\hline N9-F & GAAGAATGCTCATGTTACGG & $832-851$ & 400 \\
\hline N9-R & TGACTAGTGTGTGTCATTGCTA & 929-950 & 400 \\
\hline N9-P-W & Cy5-ATTGGCAGGGCTCAAATAGACCAGT-BHQ3 & 887-911 & 400 \\
\hline N9-P-M & VIC-GCACATGCAAGGACA-MGB & $872-886$ & 400 \\
\hline
\end{tabular}

${ }^{a} F A M$, 6-carboxyfluorescein; Cy5, cyanine 5; ROX, 6-carboxy-X-rhodamine; MGB, minor groove binding; $B H Q$, Black Hole Quencher; $Y=T$ or $C, R=A$ or $G, K=G$ or $T$, $\mathrm{D}=\mathrm{A}$ or $\mathrm{T}$ or $\mathrm{G}$

${ }^{b}$ Nucleotide position is based on the ORF of HA and NA genes of A/Anhui/1/2013(H7N9) (GISAID accession: EPI_ISL_138739) except the probe H7-P-M, which is based on the HA gene of A/Guangdong/Th005/2017(H7N9) (GISAID accession: EPI_ISL_250424)

\section{Quantitative reverse transcription polymerase chain} reaction

The samples (both clinical and cultured) were tested by a one-step multiplex qRT-PCR in an ABI QuantStudio Dx Real-Time cycler (Applied Biosystems, Foster City, USA). The One Step PrimeScript ${ }^{\mathrm{Tm}}$ RT-PCR Kit (Takara, Dalian, China) was used as follows: $0.8 \mu \mathrm{L}$ enzyme mixture (including reverse transcriptase [RT] and Taq polymerase), $10 \mu \mathrm{L} 2 \times$ One Step RT-PCR buffer III, $0.4 \mu \mathrm{L}$ of each primer and probe for NA gene, $0.6 \mu \mathrm{L}$ of each primer for $\mathrm{HA}$ gene, $0.6 \mu \mathrm{L}$ of the universal probe for HA gene (H7-P-W), $0.8 \mu \mathrm{L}$ of the specific probe for HP-H7 gene (H7-P-M), $0.8 \mu \mathrm{L}$ RNase free water, and $5 \mu \mathrm{L}$ RNA (total $20 \mu \mathrm{L} /$ reaction mixture). The concentration of all the primers and probes was $20 \mu \mathrm{M}$. The qRT-PCR assay conditions were as follows: reverse transcription for $5 \mathrm{~min}$ at $42{ }^{\circ} \mathrm{C} ; 10 \mathrm{~s}$ at $95{ }^{\circ} \mathrm{C}$ for reverse transcriptase inactivation and DNA polymerase activation followed by 40 cycles of $5 \mathrm{~s}$ at $95^{\circ} \mathrm{C}$ and $30 \mathrm{~s}$ at $60^{\circ}$ $\mathrm{C}$ (annealing-extension step). The data were analyzed using the QuantStudio ${ }^{\text {тм }}$ Real-Time PCR Software (Applied Biosystems, Foster City, USA). Commercial qRT-PCR kits for the detection of HP-H7N9 viruses were also used (Mabsky Biotech Co., Ltd., Shenzhen, China; Zhengzhou Zhongdao Biotechnology Co., Ltd., Henan, China) following the manufacturers' instructions. All samples were analyzed in triplicate with three independent runs.

\section{Clinical samples}

Sputum samples were obtained from ten confirmed cases of H7N9 infection in Shenzhen Third People's Hospital and Yunnan Center for Disease Control and Prevention. Viral RNA was extracted using the QIAamp RNA Viral Kit (Qiagen, Heiden, Germany) according to the manufacturer's instruction.

\section{Results}

\section{Design of the primer-probe set}

First, we downloaded and compared the HA genes of the $\mathrm{HP}$ - and LP-H7N9 virus. The HA genes of the HP-H7N9 virus possessed either a KRTA, KRIA, or KRAA insertion with a nucleic acid 12 bp in size, 5'-AAA CGG A(G)C(T)T GCG-3'. Thus, we designed the forward $(\mathrm{H} 7-\mathrm{F})$, reverse $(\mathrm{H} 7-\mathrm{R})$ primers covering this region, and a probe (H7-P-M) which can specifically recognize the specific insertion. Additionally, a universal probe (H7-P-W) targeting both the HP- and LP-H7N9 within the same region was designed to identify the presence of $\mathrm{H} 7$. We then downloaded and compared the NA genes of the H7N9 viruses, selected the forward (N9-F), reverse (N9-R) primers covering the R292K mutation region, and designed a probe (N9-P-M) which can specifically recognize the $\mathrm{R} 292 \mathrm{~K}$ mutation. Meanwhile, a universal probe (N9-P-W) within the same region was designed to detect the presence of N9 genes. The four probes were labeled with four types of different fluorescence. The oligonucleotide sequences, genome positions, labeled fluorescence of the primers and probes for the multiplex assay are listed in Table 1.

\section{Specificity of the multiplex qRT-PCR assay}

The primer-probe set was optimized as a single-well method for H7N9 detection by one-step multiplex qRT-PCR method as described in the Methods section, and the optimized concentrations of the primers and probes are shown in Table 1. To test the specificity of our multiplex qRT-PCR assay, four different H7N9 viruses (LP-H7N9 without NAI-resistance mutation, LP-H7N9 with NAI-resistance mutation, HP-H7N9 without NAI-resistance mutation and HP-H7N9 with NAI-resistance mutation) were used (the identities of viruses used are listed in Table 2). The universal probes of H7 and N9 successfully detected all four phenotypes of H7N9 virus (Fig. 1). Meanwhile, specific probes targeting 
Table 2 The influenza virus strains used in the present study

\begin{tabular}{|c|c|c|c|c|c|c|c|c|c|}
\hline \multirow{2}{*}{$\begin{array}{l}\text { Types } \\
\text { and } \\
\text { subtypes }\end{array}$} & \multirow{2}{*}{$\begin{array}{l}\text { Reference } \\
\text { strains }\end{array}$} & \multirow[t]{2}{*}{ GISAID NO. } & \multirow[t]{2}{*}{ HP/LP AIV } & \multirow[t]{2}{*}{$292 \mathrm{R} / \mathrm{K}$ in NA } & \multirow{2}{*}{$\begin{array}{l}\text { Virus titer } \\
\left(T_{C I D} / D_{50} / \mathrm{mL}\right)\end{array}$} & \multicolumn{4}{|c|}{ qRT-PCR assays } \\
\hline & & & & & & $\mathrm{H} 7-\mathrm{W}$ & H7-M & N9-W & N9-M \\
\hline H7N9 & SZ/Th003 & EPI_ISL_250313 & LP & $R$ & $2 \times 10^{6}$ & $14.38 \pm 0.12$ & $U^{c}$ & $14.44 \pm 0.21$ & $U$ \\
\hline H7N9 & SZ/Th004 & EPI_ISL_250314 & $L P$ & K & $2 \times 10^{6}$ & $14.37 \pm 0.36$ & $U$ & $15.05 \pm 0.23$ & $14.15 \pm 0.55$ \\
\hline H7N9 & GD/Th005 & EPI_ISL_250312 & HP & $\mathrm{R}$ & $2 \times 10^{6}$ & $15.61 \pm 0.48$ & $15.06 \pm 0.49$ & $15.45 \pm 0.19$ & $U$ \\
\hline H7N9 & SZ/Th007 & EPI_ISL_259757 & $H P$ & K & $2 \times 10^{6}$ & $13.91 \pm 0.24$ & $13.87 \pm 0.56$ & $14.45 \pm 0.15$ & $13.55 \pm 0.09$ \\
\hline $\mathrm{H} 3 \mathrm{~N} 2$ & CAS0001 & $-^{a}$ & $-^{\mathrm{b}}$ & $-{ }^{\mathrm{b}}$ & $-^{a}$ & $U$ & $U$ & $U$ & $U$ \\
\hline $\mathrm{H} 1 \mathrm{~N} 1$ & CA04 & FJ966082 & $-{ }^{b}$ & $\mathrm{R}$ & $-^{a}$ & U & U & $U$ & $U$ \\
\hline H5N6 & Th001 & EPI_ISL_205503 & HP & $\mathrm{R}$ & $-^{a}$ & $U$ & $U$ & $U$ & $U$ \\
\hline H9N2 & 04.15SZBAXQ005 & EPI_ISL_199448 & $L P$ & $R$ & $-^{a}$ & $U$ & $U$ & $U$ & $U$ \\
\hline Flu-B & Victoria & $-^{a}$ & $-^{b}$ & $-^{\mathrm{b}}$ & $-^{a}$ & $U$ & $U$ & $U$ & $U$ \\
\hline Flu-B & Yamagata & $-^{a}$ & $-^{b}$ & $-^{\mathrm{b}}$ & $-^{a}$ & U & U & $U$ & $U$ \\
\hline
\end{tabular}

anot available

${ }^{b}$ not applicable

'undetected

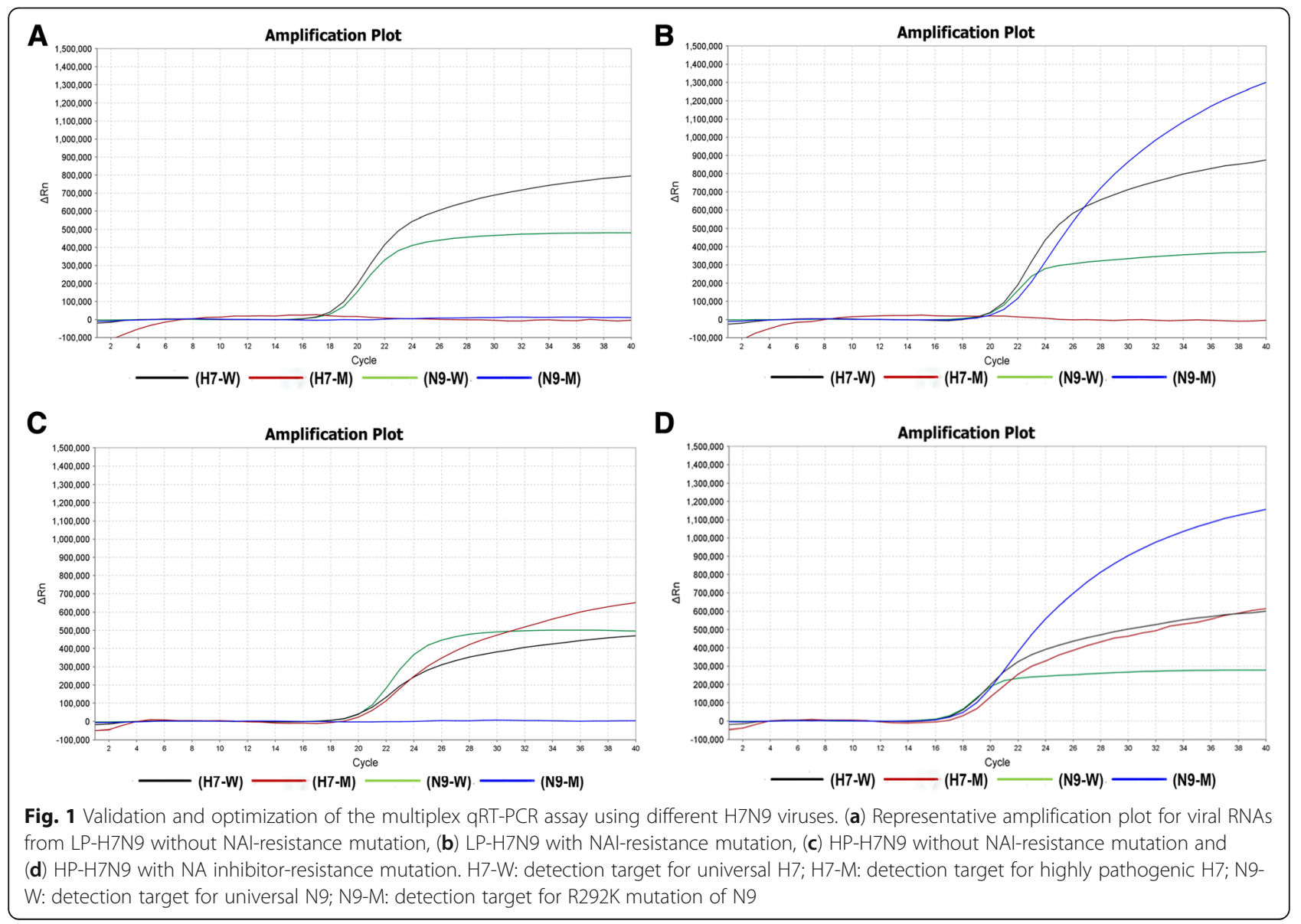


HP-H7 or N9-K292 specifically recognized the corresponding phenotypes of H7N9 viruses without any nonspecific amplification. In addition, there were also no nonspecific amplification when tested against other influenza viruses (including H1N1, H3N2, H5N6, H6N6 and H9N2 subtype of influenza $\mathrm{A}$ and influenza B) (Table 2).

\section{Sensitivity of the multiplex qRT-PCR assay}

The detection limit of the multiplex qRT-PCR assay was evaluated by quantitative standards from a PGEM-T vector expressing the target sequence of the HP-H7 and N9-K292 genes, or viral RNAs prepared from serial ten-fold dilutions of the four different phenotypes of H7N9 viral stocks. The multiplex qRT-PCR method using DNA standards as template showed that $\mathrm{Ct}$ values were similar among the four targets, and the linear range was between $1 \times 10^{6}$ to $1 \times 10^{1}$ molecules, respectively. Moreover, the regression coefficients $\left(R^{2}\right)$ values were above 0.99 , indicating that the assay was both accurate and precise over this range (Fig. 2). The limit of detection was determined to be 50 genome-equivalent copies per reaction, based on specific amplification curves (Fig. 2a) and the standard curve (Fig. 2b).

Meanwhile, RNA samples were extracted from ten-fold serial dilutions of four phenotypes of stock H7N9 viruses ranging from $2 \times 10^{6}$ to $2 \times 10^{-2}$ $\mathrm{TCID}_{50} / \mathrm{mL}$, and were used to test the detection limit (Figs. 3 and 4). Results showed that the detection limit of the multiplex qRT-PCR assay was similar among the four H7N9 viruses $\left(2.8 \times 10^{-2} \mathrm{TCID}_{50}\right)$ per reaction, except for LP-H7N9 without NAI-resistance, which was $2.8 \times 10^{-3} \mathrm{TCID}_{50}$ per reaction. The titers
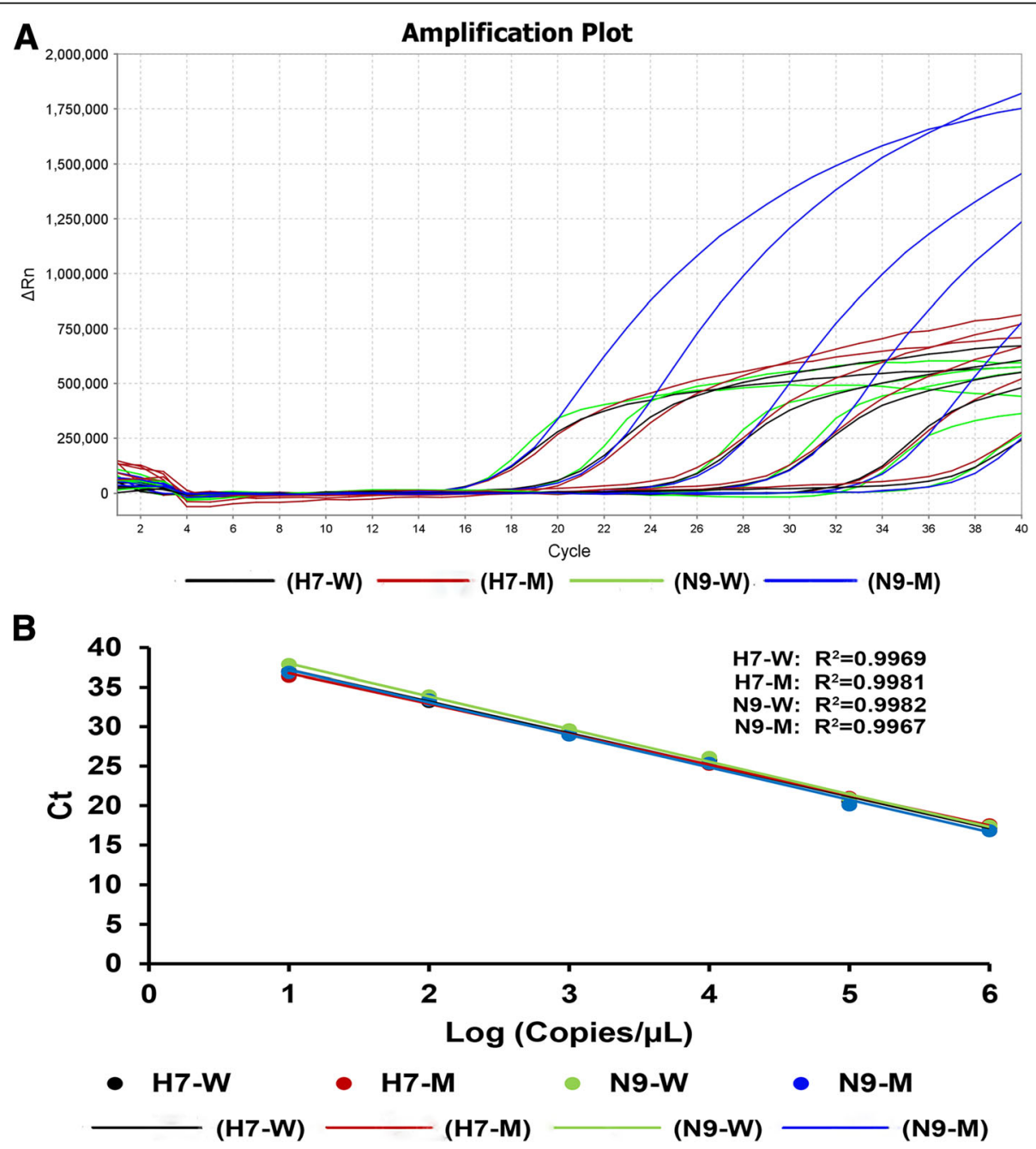

Fig. 2 Sensitivity of the multiplex qRT-PCR assay using DNA standards. (a) Representative amplification plot of the different concentrations of plasmids expressing the targeted $\mathrm{H} 7$ or N9 genes (10-fold dilutions). (b) Standard curve for ten-fold serial dilutions of the DNA standards. The log numbers of plasmids (Copies/ $\mathrm{LL}$ ) are expressed linearly on the $x$-axis, whereas Ct values obtained from qRT-PCR are expressed linearly on the $y$ axis. H7-W, H7-M, N9-W and N9-M are defined the same with Fig. 1 


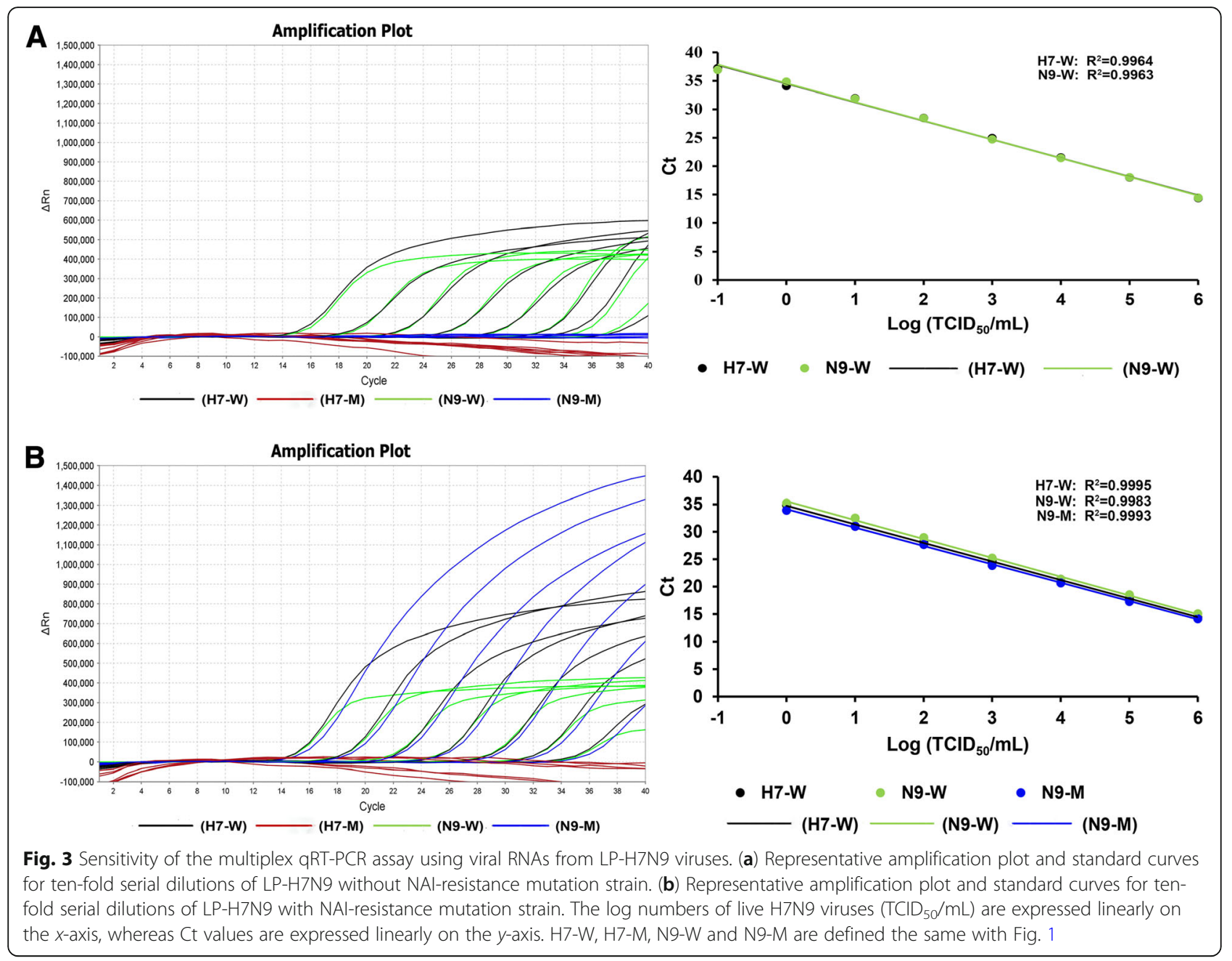

correlated well with the obtained Ct values $\left(R^{2}>0.99\right)$ (Figs. 3 and 4).

\section{Validation of the multiplex qRT-PCR assay in clinical samples}

To validate the assay with clinical samples, we tested 10 sputum specimens obtained from 10 patients confirmed to be infected with influenza A (H7N9) virus during the fifth wave (Table 3). As expected, all samples tested positive for H7N9 viruses with similar Ct values compared to two commercial kits (Table 3). Furthermore, samples from patients SZ05, SZ07 and SZ08 were determined to be HP-H7N9; and samples from patients SZ04, SZ07 and SZ08 were determined to have NAI-resistance mutations. These results were confirmed by Sanger sequencing.

\section{Discussion}

Previous studies have revealed that the HP-H7N9 virus has caused several outbreaks in poultry farms, in which over 110,000 poultry were found dead in at least 10 provinces [29]. Meanwhile, human infections in rural areas were mostly associated with exposure to sick and dead poultry [8], and the HP-H7N9 variants were also found in the live poultry markets (LPMs) and environment of the human patients [2, 30,31]. In terms of this situation, the rapid and accurate detection method of HP-H7N9 strains is in urgent need. Recently, one group has developed a duplex qRT-PCR assay to detect both LP-H7 and HP-H7 genes [26]. However, another two novel insertion mutations with "KRIA" or "KRAA" motif in the cleavage site has been found for the HP-H7N9 [2, $8,11,30]$, their probe targeting HP-H7 could not cover all the mutations of HP-H7N9 strains. Furthermore, besides H7, our assay also included the detection target of N9 gene, which could further confirm the presence of H7N9 virus. Except for the broader coverage of probes for $\mathrm{HP}-\mathrm{H} 7$ and the additional detection target of N9, our assay also possessed an excellent sensitivity. Together, our assay may represent an upgrade of the detection method for HP-H7N9 viruses.

The emergence of an NAI-resistance mutation is temporally associated with a rebound of virus load, treatment 


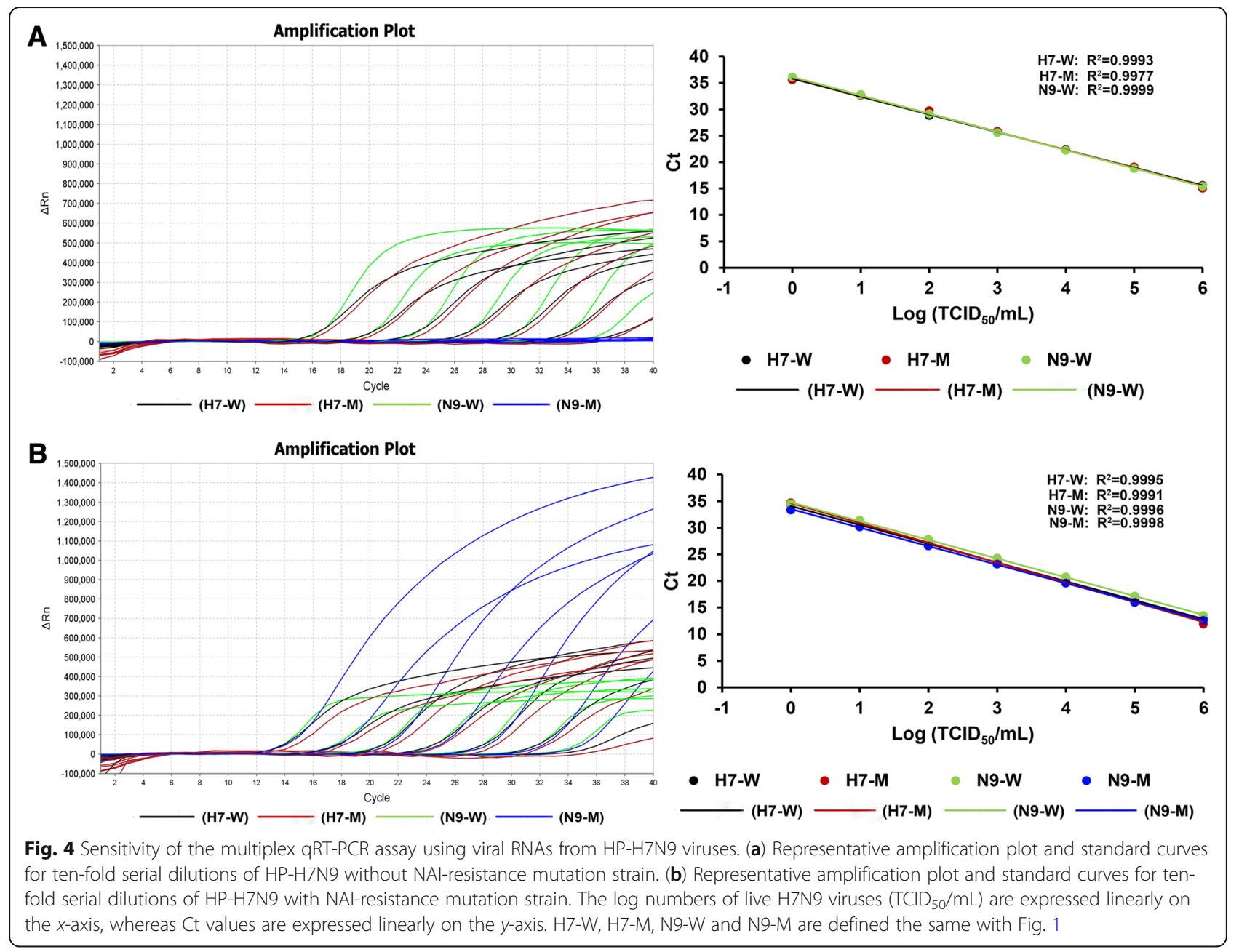

Table 3 Detection of H7N9 virus in the clinical samples

\begin{tabular}{|c|c|c|c|c|c|c|c|}
\hline \multirow{2}{*}{$\begin{array}{l}\text { Clinical } \\
\text { samples }\end{array}$} & \multicolumn{4}{|l|}{$\mathrm{H} 7(\mathrm{HP} / \mathrm{LP})^{\mathrm{a}}$} & \multicolumn{2}{|l|}{ N9 $(292 R / K)$} & \multirow[t]{2}{*}{ GISAID NO. } \\
\hline & Multiplex qRT-PCR & Kit-1 & Kit-2 & $\begin{array}{l}\text { Sanger } \\
\text { sequencing }\end{array}$ & Multiplex qRT-PCR & $\begin{array}{l}\text { Sanger } \\
\text { sequencing }\end{array}$ & \\
\hline SZ01 & $32.5(\mathrm{LP})$ & $32.46(L P)$ & $33.28(L P)$ & $L P$ & $R$ & $\mathrm{R}$ & EPI_ISL_250424 \\
\hline SZ02 & $35.92(L P)$ & $35.85(L P)$ & $35.52(\mathrm{LP})$ & $L P$ & $\mathrm{R}$ & $\mathrm{R}$ & EPI_ISL_250425 \\
\hline SZ03 & $31.79(L P)$ & $31.26(L P)$ & $31.9(\mathrm{LP})$ & $L P$ & R & $\mathrm{R}$ & EPI_ISL_250313 \\
\hline SZO4 & $26.74(L P)$ & $27.16(L P)$ & $27.05(L P)$ & $L P$ & K & K & EPI_ISL_250314 \\
\hline SZ05 & $26.04(H P)$ & $26.74(\mathrm{HP})$ & $25.28(\mathrm{HP})$ & $H P$ & $R$ & $\mathrm{R}$ & EPI_ISL_250312 \\
\hline SZ06 & $26.91(L P)$ & $26.35(L P)$ & $26.43(L P)$ & $L P$ & R & $\mathrm{R}$ & EPI_ISL_250315 \\
\hline SZ07 & $28.57(H P)$ & $27.95(\mathrm{HP})$ & $28.91(\mathrm{HP})$ & $\mathrm{HP}$ & K & K & EPI_ISL_259757 \\
\hline SZ08 & $19.81(H P)$ & $20.29(\mathrm{HP})$ & $20.22(\mathrm{HP})$ & $\mathrm{HP}$ & K & K & EPI_ISL_266936 \\
\hline YN01 & $27.35(L P)$ & $28.31(L P)$ & $29.05(L P)$ & LP & $\mathrm{R}$ & $\mathrm{R}$ & EPI_ISL_250316 \\
\hline YN02 & $36.03(L P)$ & $35.22(L P)$ & $35.13(L P)$ & $L P$ & R & $\mathrm{R}$ & EPI_ISL_250317 \\
\hline
\end{tabular}

The $\mathrm{Ct}$ values of the commercial kits and our developed method for universal $\mathrm{H} 7$ were shown 
failure and a poor clinical outcome [16]. Therefore, identification of the NAI-mutation in time may increase the cure rate for H7N9 infections. Resistance to NAIs in particular has important implications, as this class of agent is most widely used for treatment and outbreak control. Accordingly, appropriate laboratory methods for the continuous efforts of laboratory surveillance are of great importance [12]. Currently, the gold standard methods for antiviral resistance screening include phenotypic and genotypic methods using NA-Star assay and Sanger sequencing, respectively $[32,33]$. While both of these methodologies are labor intensive, time-consuming and expensive, suggesting the need for a rapid, high-throughput approach to influenza drug resistance testing. Although an SNP real-time RT-PCR for detection of NAI-resistance mutation has been developed [27], the application may be restricted in its delayed detection after the identification of H7N9 and the limit of detection. As described in our assay, we can directly determine the presence of LP- or HP-H7N9 viruses and simultaneously identify the NAI resistance with higher detection limit, which significantly improve the efficiency and performance of detection.

\section{Conclusions}

In conclusion, we developed and validated a rapid, singlereaction, one-step, quadruple real-time qRT-PCR to simultaneously detect the presence of H7N9 and further identify the HP- and NAI-resistance strains with excellent performance in specificity and sensitivity. As the ongoing circulation of H7N9 viruses among poultry, enhanced surveillance is critical to guide prevention and control efforts. This assay will be of great use in monitoring the circulation of HP-H7N9 and NAI-resistant virus strains during AIV surveillance and the treatment of patients with NAIs to prevent persistent viral replication and severe inflammatory reactions.

\section{Abbreviations \\ AIV: Avian influenza virus; HP: Highly pathogenic; LP: Low pathogenic; NAI: Neuraminidase inhibitor; qRT-PCR: Quantitative reverse transcript polymerase chain reaction; SNP: Single nucleotide polymorphism; $\mathrm{TCID}_{50}$ : 50\% tissue culture infectious dose}

\section{Acknowledgments}

We thank the staff of our hospital for their assistance in sample collection and laboratory work.

\section{Funding}

This work was supported by grants from the National Key Research and Development Project of China (2016YFE0205800), National Science and Technology Major Project (2016ZX10004222), Emergency Technology Research Issue on Prevention and Control for Human Infection with A(H7N9) Avian Influenza Virus (10600100000015001206), Sanming Project of Medicine in Shenzhen (ZDSYS201504301534057), Shenzhen Science and Technology Research and Development Project (JCYJ20160427153238750 and JCYJ20160427151920801), intramural special grant for influenza virus research from the Chinese Academy of Sciences (KUZD-EW-L15) and Science and Technology plan project of Shenzhen (201506048 and 20160625). G.F.G. is a leading principal investigator of the NSFC Innovative Research Group (81621091). Y.B. is supported by the Youth Innovation Promotion Association of Chinese Academy of Sciences (2017122). The funding bodies had no roles in the design of the study, or the collection, analysis and interpretation of data, or writing the manuscript.

\section{Availability of data and materials}

Full-length genome sequences of the ten H7N9 viruses isolated from the clinical samples in our study have been deposited into GISAID EpiFlu: EPI_ISL_250312-17, EPI_ISL_250424-25, EPI_ISL_259757, and EPI_ISL_266936.

\section{Authors' contributions}

$Y B$ and $Y Y$ designed the experiments. YY, SL, GW, SM and ZX performed the experiments and results analysis. $X Z, W X, H L, H Z, J L$ and $Q Z$ recruited the patients, performed clinical monitoring, and provided clinical expertise. WL, YL and GFG provided technical support. YY, GW and YB wrote the manuscript, and all authors provided critical review and approved the manuscript.

\section{Ethics approval and consent to participate}

The study was performed in accordance with guidelines approved by the Ethics Committees from Shenzhen Third People's Hospital (SZTHEC2016001) and Yunnan Center for Disease Control and Prevention Ethics Committee (YNCDC2017001), and verbal informed consents were obtained from all patients or patients' family members.

Consent for publication

Not applicable.

\section{Competing interests}

The authors declare that they have no competing interests.

\section{Publisher's Note}

Springer Nature remains neutral with regard to jurisdictional claims in published maps and institutional affiliations.

\section{Author details \\ 'Shenzhen Key Laboratory of Pathogen and Immunity, State Key Discipline of Infectious Disease, Second Hospital Affiliated to Southern University of Science and Technology, Shenzhen Third People's Hospital, Shenzhen 518112, China. ${ }^{2}$ CAS Key Laboratory of Pathogenic Microbiology and Immunology, Collaborative Innovation Center for Diagnosis and Treatment of Infectious Disease, Institute of Microbiology, Center for Influenza Research and Early-warning (CASCIRE), Chinese Academy of Sciences, Beijing 100101, China. ${ }^{3}$ Yunnan Center for Disease Control and Prevention, Kunming 650022, China. ${ }^{4}$ National Institute for Viral Disease Control and Prevention, Chinese Center for Disease Control and Prevention (China CDC), Beijing 102206, China. ${ }^{5}$ University of Chinese Academy of Sciences Medical School, Chinese Academy of Sciences, Beijing 101408, China.}

Received: 20 March 2018 Accepted: 1 August 2018

Published online: 15 August 2018

\section{References}

1. Gao R, Cao B, Hu Y, Feng Z, Wang D, Hu W, Chen J, Jie Z, Qiu H, Xu K, et al. Human infection with a novel avian-origin influenza a (H7N9) virus. N Engl J Med. 2013;368(20):1888-97.

2. Quan CS, Shi WF, Yang Y, Yang YC, Liu XQ, Xu W, Li H, Li J, Wang QL, Tong $Z$, et al. New threats of H7N9 influenza virus: the spread and evolution of highly and low pathogenic variants with high genomic diversity in Wave Five. J Virol. 2018:92(11). pii: e00301-18.

3. Wang X, Jiang H, Wu P, Uyeki TM, Feng L, Lai S, Wang L, Huo X, Xu K, Chen E, et al. Epidemiology of avian influenza a H7N9 virus in human beings across five epidemics in mainland China, 2013-17: an epidemiological study of laboratory-confirmed case series. Lancet Infect Dis. 2017;17(8):822-32.

4. Su S, Gu M, Liu D, Cui J, Gao GF, Zhou J, Liu X. Epidemiology, evolution, and pathogenesis of H7N9 influenza viruses in five epidemic waves since 2013 in China. Trends Microbiol. 2017;25(9):713-28.

5. WHO. Monthly risk assessment summary. 2017. http://www.who.int/ influenza/human_animal_interface/HAl_Risk_Assessment/en/. Accessed 4 Nov 2017. 
6. Liu J, Xiao H, Wu Y, Liu D, Qi X, Shi Y, Gao GF. H7N9: a low pathogenic avian influenza a virus infecting humans. Curr Opin Virol. 2014;5:91-7.

7. Yang JR, Liu MT. Human infection caused by an avian influenza a (H7N9) virus with a polybasic cleavage site in Taiwan, 2017. J Formos Med Assoc. 2017;116(3):210-2.

8. Z Zhang F, Bi Y, Wang J, Wong G, Shi W, Hu F, Yang Y, Yang L, Deng X, Jiang $S$, et al. Human infections with recently-emerging highly pathogenic H7N9 avian influenza virus in China. J Inf Secur. 2017;75(1):71-5.

9. Zhou L, Tan Y, Kang M, Liu F, Ren R, Wang Y, Chen T, Yang Y, Li C, Wu J, et al. Preliminary epidemiology of human infections with highly pathogenic avian influenza a(H7N9) virus, China, 2017. Emerg Infect Dis. 2017;23(8):1355-9.

10. Kile JC, Ren R, Liu L, Greene CM, Roguski K, luliano AD, Jang Y, Jones J, Thor S, Song $Y$, et al. Update: increase in human infections with novel asian lineage avian influenza a(H7N9) viruses during the fifth epidemic China, October 1, 2016-august 7, 2017. MMWR Morb Mortal Wkly Rep. 2017:66(35):928-32

11. Qi W, Jia W, Liu D, Li J, Bi Y, Xie S, Li B, Hu T, Du Y, Xing L et al. Emergence and adaptation of a novel highly pathogenic H7N9 influenza virus in birds and humans from a 2013 human-infecting low-pathogenic ancestor. J Virol. 2018:92(2). pii: e00921-17.

12. Li TC, Chan MC, Lee N. Clinical implications of antiviral resistance in influenza. Viruses. 2015;7(9):4929-44.

13. Marjuki H, Mishin VP, Chesnokov AP, De La Cruz JA, Davis CT, Villanueva JM, Fry AM, Gubareva LV. Neuraminidase mutations conferring resistance to oseltamivir in influenza a(H7N9) viruses. J Virol. 2015;89(10):5419-26.

14. Gubareva LV, Besselaar TG, Daniels RS, Fry A, Gregory V, Huang W, Hurt AC, Jorquera PA, Lackenby A, Leang SK, et al. Global update on the susceptibility of human influenza viruses to neuraminidase inhibitors, 20152016. Antivir Res. 2017;146:12-20.

15. Wu Y, Bi Y, Vavricka CJ, Sun X, Zhang Y, Gao F, Zhao M, Xiao H, Qin C, He J, et al. Characterization of two distinct neuraminidases from avian-origin human-infecting H7N9 influenza viruses. Cell Res. 2013;23(12):1347-55.

16. Hu Y, Lu S, Song Z, Wang W, Hao P, Li J, Zhang X, Yen HL, Shi B, Li T, et al. Association between adverse clinical outcome in human disease caused by novel influenza a H7N9 virus and sustained viral shedding and emergence of antiviral resistance. Lancet. 2013;381(9885):2273-9.

17. Nguyen HT, Nguyen T, Mishin VP, Sleeman K, Balish A, Jones J, Creanga A, Marjuki H, Uyeki TM, Nguyen DH, et al. Antiviral susceptibility of highly pathogenic avian influenza a(H5N1) viruses isolated from poultry, Vietnam, 2009-2011. Emerg Infect Dis. 2013;19(12):1963-71.

18. Govorkova EA, Baranovich T, Seiler P, Armstrong J, Burnham A, Guan Y, Peiris M, Webby RJ, Webster RG. Antiviral resistance among highly pathogenic influenza a (H5N1) viruses isolated worldwide in 2002-2012 shows need for continued monitoring. Antivir Res. 2013;98(2):297-304.

19. Kawai N, Ikematsu H, Iwaki N, Kondou K, Hirotsu N, Kawashima T, Maeda T, Tanaka O, Doniwa K, Iwakuni O, et al. Persistence of pandemic influenza H1N1 virus in young patients after oseltamivir therapy in the 2009-2010 season: a comparison with seasonal H1N1 with or without H275Y mutation. J Infect Chemother. 2012;18(2):180-6.

20. Vavricka CJ, Li Q, Wu Y, Qi J, Wang M, Liu Y, Gao F, Liu J, Feng E, He J, et al. Structural and functional analysis of laninamivir and its octanoate prodrug reveals group specific mechanisms for influenza NA inhibition. PLoS Pathog. 2011;7(10):e1002249.

21. Kawai N, Ikematsu H, Iwaki N, Kondou K, Hirotsu N, Kawashima T, Maeda T, Tanaka O, Doniwa K, Kashiwagi S. Clinical effectiveness of oseltamivir for influenza a(H1N1) virus with $\mathrm{H} 274 \mathrm{Y}$ neuraminidase mutation. J Inf Secur. 2009;59(3):207-12

22. Hurt AC, lannello P, Jachno K, Komadina N, Hampson AW, Barr IG, McKimmBreschkin JL. Neuraminidase inhibitor-resistant and -sensitive influenza B viruses isolated from an untreated human patient. Antimicrob Agents Chemother. 2006;50(5):1872-4

23. Meijer $A$, Jonges $M$, van Beek $P$, Swaan $C M$, Osterhaus AD, Daniels RS, Hurt AC, Koopmans MP. Oseltamivir-resistant influenza a(H1N1)pdm09 virus in Dutch travellers returning from Spain, august 2012. Euro Surveill. 2012; 17(36):20266.

24. Ke C, Mok CKP, Zhu W, Zhou H, He J, Guan W, Wu J, Song W, Wang D, Liu J, et al. Human infection with highly pathogenic avian influenza a(H7N9) virus. China Emerg Infect Dis. 2017;23(8):1332-40.
25. Danqi B, Li Z, Liu Q, Richt JA. H7N9 avian influenza a virus in China: a short report on its circulation, drug resistant mutants and novel antiviral drugs. Expert Rev Anti-Infect Ther. 2017;15(8):723-7.

26. Jia W, Cao C, Lin Y, Zhong L, Xie S, Wang X, Yin S, Xu Z, Dai Y, Li Z, et al. Detection of a novel highly pathogenic $\mathrm{H} 7$ influenza virus by duplex realtime reverse transcription polymerase chain reaction. J Virol Methods. 2017; 246:100-3.

27. Wang W, Song Z, Guan W, Liu Y, Zhang X, Xu L, Li J, Yuan Z, Hu Y. PCR for detection of oseltamivir resistance mutation in influenza a(H7N9) virus. Emerg Infect Dis. 2014;20(5):847-9.

28. Reed $\amalg$, Muench $\mathrm{H}$. A simple method of estimating fifty percent endpoints. Am J Hyg. 1938;27:493-7.

29. OIE. Update on avian influenza in animals (types H5 and H7). 2017. http:// www.oie.int/en/animal-health-in-the-world/update-on-avian-influenza/2017/. Accessed 4 Nov 2017.

30. Yang L, Zhu W, Li X, Chen M, Wu J, Yu P, Qi S, Huang Y, Shi W, Dong J et al. Genesis and spread of newly emerged highly pathogenic H7N9 avian viruses in mainland China. J Virol. 2017;91(23). pii: e01277-17.

31. Shi J, Deng G, Kong H, Gu C, Ma S, Yin X, Zeng X, Cui P, Chen Y, Yang H, et al. H7N9 virulent mutants detected in chickens in China pose an increased threat to humans. Cell Res. 2017;27(12):1409-21.

32. Meijer A, Lackenby A, Hay A, Zambon M. Influenza antiviral susceptibility monitoring activities in relation to national antiviral stockpiles in Europe during the winter 2006/2007 season. Euro Surveill. 2007;12(4):E3-4.

33. Wong S, Pabbaraju K, Wong A, Fonseca K, Drews SJ. Development of a realtime RT-PCR assay for detection of resistance to oseltamivir in influenza a pandemic (H1N1) 2009 virus using single nucleotide polymorphism probes. Virol Methods. 2011:173(2):259-65.

Ready to submit your research? Choose BMC and benefit from:

- fast, convenient online submission

- thorough peer review by experienced researchers in your field

- rapid publication on acceptance

- support for research data, including large and complex data types

- gold Open Access which fosters wider collaboration and increased citations

- maximum visibility for your research: over $100 \mathrm{M}$ website views per year

At $\mathrm{BMC}$, research is always in progress.

Learn more biomedcentral.com/submissions 